\title{
Noise pollution modeling associated with the operations of the Sarakhs airport
}

\author{
Amir Esmael Forouhid \\ Department of Civil Engineering, Parand Branch, Islamic Azad University, Parand, Iran \\ E-mail: amiresmaelf@yahoo.com
}

Received 28 January 2018; accepted 2 April 2018

DOI https://doi.org/10.21595/vp.2018.19683

Check for updates

Abstract. In this paper, a model for the noise pollution of Sarakhs Airport has been calibrated with the use of integrated noise modeling. With result of this modeling we can understand the regions that have high noise in comparing with allowable standard value. At the end explain some methods for decreasing the effects of noise pollution of the airport.

Keywords: noise, Sarakhs, airport, pollution, aircraft.

\section{Introduction}

The issue of noise pollution from the two perspectives is striking. In terms of the effect of short term it can be fitted to a damage for the moment on the power of the hearing pointed out that after a few moments. But from the perspective of long term compensation effects characterizes the people and different hurts enter fitted in to a few examples of the forklift will be referred. The reason is that in the whole world to the noise pollution caused by aircraft and user design right around it is widely discussed that it is hoped this will be damage and complications caused by noise pollution on the improve communities.

\section{Impact of noise pollution}

There are health consequences of elevated sound levels. Noise pollution of airports or other noise can cause hearing impairment, hypertension, ischemic heart disease, annoyance, sleep disturbance, and decreased school performance. Although some hearing loss occurs naturally with age, in many developed nations the impact of noise is sufficient to impair hearing over the course of a lifetime Elevated noise levels can create stress, increase workplace accident rates, and stimulate aggression and other anti-social behaviors. Airport noise has been linked to high blood pressure. Numerous studies have been undertaken which assess the effects of noise on humans, animals, and structures [1]. The consequences of exposure to high levels of noise, or simply higher levels of noise for extended duration, range from annoyance to loss of hearing [2]. Annoyance is defined as "a feeling of displeasure evoked by noise". While $55 \mathrm{~dB}$ has been identified as an annoyance level, $65 \mathrm{~dB}$ become a more generally accepted threshold criterion for annoyance. That being said, levels of annoyance are highly subjective [2]. A typical conversation is around $60 \mathrm{~dB}$. Note that an increase from a typical conversation to the sound level of a vacuum cleaner is only $10 \mathrm{~dB}$. Furthermore, an increase of $20 \mathrm{~dB}$ is representative of a motorcycle at 25 feet.

The time of day that a flight occurs plays a large role in determining the level of annoyance. Annoyance from flights during typical working hours may be minimal. If that same flight occurs in the middle of the night, the annoyance may increase considerably. It should be re-emphasized that the psychological effects of noise are highly subjective [2]. The physiological effects of noise pollution on the body offer material evidence of the consequences of noise pollution. Noise pollution has been shown to cause hearing loss, elevated blood pressure, sleep loss, stress, distraction, cardiovascular problems, social behavioral problems, and an overall decrease in quality of living. Lastly, noise pollution has proven to be detrimental to property values in impacted area [3]. With consideration to the noise, it is necessary for the residents near airports to limit this pollution near their home.

The FAA has no current standardized directive to ease noise annoyance for the flight paths of 
arriving and departing aircraft [4]. Flight path guidelines would ensure that residents surrounding airports would be subjected to the minimum noise pollution from departing and arriving flights.

\section{Airport noise modeling in this study}

The need to model the data of a specific study on the airport's operations. Get this information because of the methodical as by airport Civil Aviation Organization country data are not gathered, it is often difficult. Therefore, we must collect certain information for specific loaders. Input of data related to airplane operations, activity at the airport using the mean values during the period of the desired expression in time.

This data includes the following items are fitted:

1) Physical specifications of the bonds, including any airport flight lines moved ahead meeting or earlier.

2) Percent use the flying runway.

3) The number of airplane flying fleet operations based on the type of airplane noise.

4) Separation of daily and nightly operations depending on the type of airplane.

The INM computer program calculates noise exposure contours in the vicinity of airports by using a large database of aircraft flight performance and acoustic data along with airport-specific user-input data. Data was modeled between March 2014 to March 2015.

\section{Sarakhs airport specification}

Sarakhs Airport is located in the northeast of IRAN. Tables below show the Sarakhs airport parameters [5].

Table 1. Information of Sarakhs international airport

\begin{tabular}{|l|l|c|l|}
\hline Location & \multicolumn{3}{|l|}{ Mashhad city in the north east of IRAN } \\
\hline Code & International \\
\hline Reference temperature (C) & 18.1 \\
\hline Runway (m) & 3951 & \multicolumn{3}{l|}{} \\
\hline Height from sea level (ft) & 953 & \multicolumn{3}{l|}{} \\
\hline & \multicolumn{4}{l|}{} \\
\hline & TODA (m) & ASDA (m) & Runway \\
\hline TORA (m) & 3951 & 3951 & 14 \\
\hline 3883 & 3939 & 3939 & 32 \\
\hline 3883 & & \multicolumn{2}{|l|}{ X point } \\
\hline & Y point & E 61 03 08 \\
\hline Runway & N 36 30 57 & E 61 04 40 \\
\hline 14 & N 36 29 11 &
\end{tabular}

\section{Modeling of aircraft noise}

Using a basic information ever was needed and should be fitted in software used to start entering data in the INM application fitted.

Step one: enter primary information.

The second step: enter the profile of the runway.

The third step: enter the information on the type of aircraft.

The fourth step: enter the desired flight paths.

In the flight path of aircraft tracks and types that directly, a workflow, in the form of the circle is considered to be fitted and specifications on each of the routes, such as the angle of the flow to be fitted.

Step five: enter the information for the analysis of noise pollution.

In the final step must enter the number of daily and night events. This mode should be used to 
view the type of aircraft and repeat it day and night and see if you consider the average coefficient. In Table 2, input data for aircrafts in the Sarakhs is described.

Table 2. Input data for aircrafts in the Sarakhs

\begin{tabular}{|c|c|c|}
\hline Aircraft & Internal usage (percent) & International usage (percent) \\
\hline Fokker 100 & 20 & 5 \\
\hline Boeing 727 & 40 & \\
\hline Cessena & 20 & 20 \\
\hline Airbus 300 & 40 & \\
\hline Airbus 318/319/320/321 & & 10 \\
\hline Airbus310 & 40 & \\
\hline Airbus 330 & & \\
\hline
\end{tabular}

In Fig. 1, presents a schematic layout of the result of noise contours in the Google Earth map in Sarakhs airport.

In Table 3, standard of noise levels in regions is shown
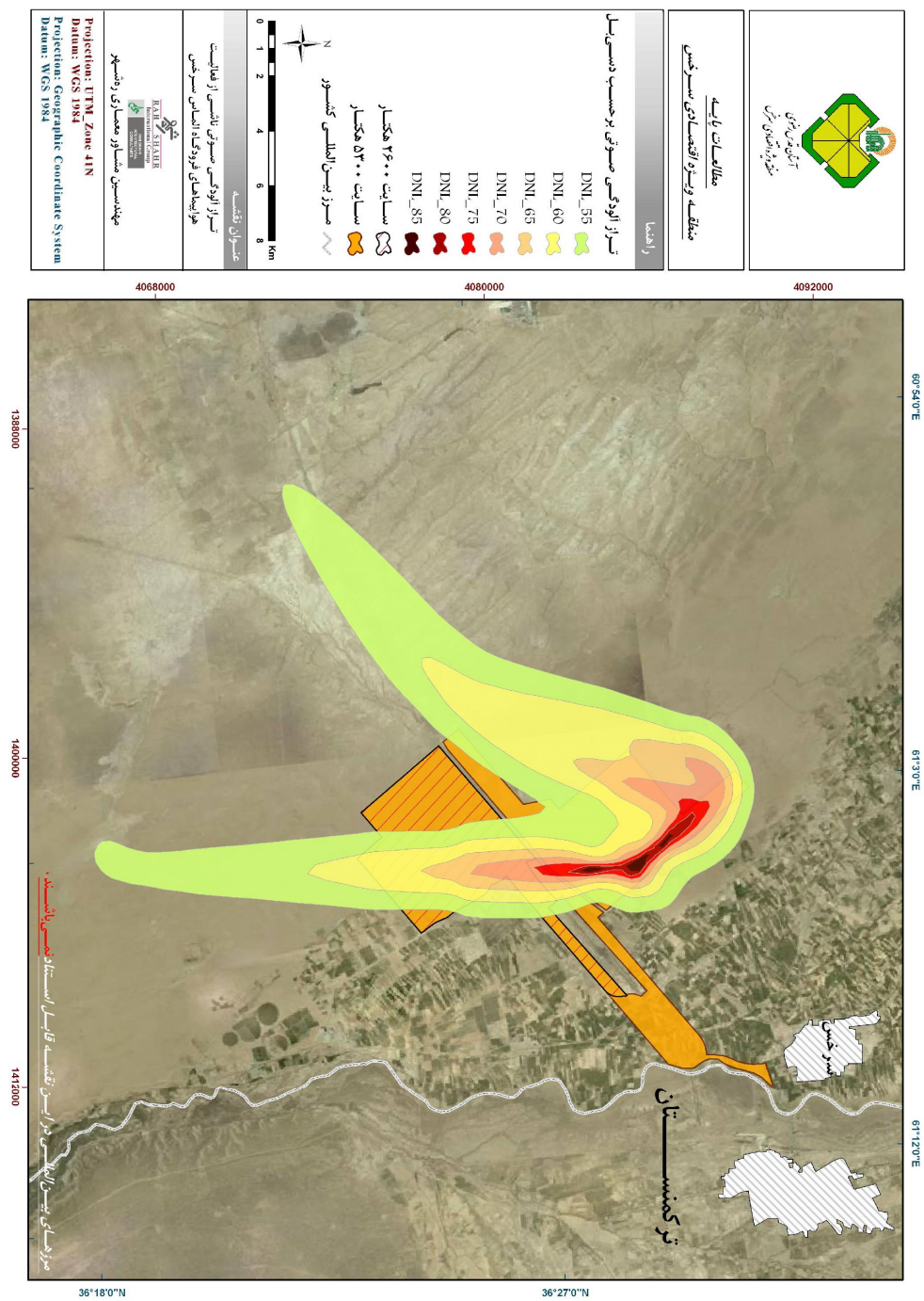

Fig. 1. Contours of the noise around the airport 
Table 3. Standard for noise values [7]

\begin{tabular}{|c|c|c|}
\hline Night $(10 \mathrm{pm}-7 \mathrm{am})(\mathrm{Db})$ & Day $(7 \mathrm{am}-10 \mathrm{pm})(\mathrm{Db})$ & Type of region \\
\hline 45 & 55 & Residential region \\
\hline 50 & 60 & Residential-commercial region \\
\hline 55 & 65 & commercial region \\
\hline 60 & 70 & Residential-industry region \\
\hline 65 & 75 & industry region \\
\hline
\end{tabular}

\section{Conclusions}

The major innovation from the Sarakhs airport study is for noise management in the air-transport industry in IRAN.

Ways to reduce and control the noise pollution in the Sarakhs airport are as follows:

- Active protection: in order to reduce noise at the source.

- Passive protection: the trick to the holder fitted low down noise during its release. (Such as retaining artificial tunnel, land-use change and the use of vegetation and etc.).

- Reduce the noise of the resulting from aircraft aerodynamics.

This type of noise pollution the effect of air mass encounters with aircraft control surfaces and the existence of a body that comes with speed and low altitude or flying an airplane (air molecules because of compression).

- Noise pollution caused by aircraft take-off and meeting time.

For different types of planes that have a relatively high noise pollution, such as the Fokker 100 and Airbus in terms of limitations on the time we stood up and.

- Change the way takeoff and.

Using the second runway currently in use may not be fitted. So, this case is a little bit in terms of the Executive is impossible.

- Steps down the length of the limited flight.

- Change the flight path.

- Change the runway direction for landing.

- Control of operation (run up).

Hence, innovations from the study will contribute to:

- Reducing the negative noise impact around airports including harmful health effects

- Improving the community response to airport operations

- Improving the quality of life of its citizens.

Of the things that in most countries of the world is running the design attractive and impressive sound barriers on the grounds of the airport.

The purpose of this design is that the obstacles to the control of noise pollution as flight operations on the noise around the airport for the user that it is low, more residents.

Urban management can use traffic control, management of urban construction land change and use of vegetation in order to control noise pollution. Traffic control consists of a one-way street up from the street and other business vehicles, fully fitted, fitted range of urban area classification, the use of a belt road, control and guidance tools.

Studies have shown that the jungle suitable work can be good protection against noise due to ground operation provide airport. While the effects of the noise caused by it in the future impact on residents near fitted around airports is the result of this thread should be for a total of Iranian airports for a comprehensive plan to be studied.

\section{References}

[1] Hsu C. I., Lin P. H. Performance assessment for airport noise charge policies and airline network adjustment response. Transportation Research Part D: Transport and Environment, Vol. 10, 2005, p. 281-304. 
[2] Hume K., Gregg M., Thomas C., Terranova D. Complaints caused by aircraft operations: an assessment of annoyance by noise level and time of day. Journal of Air Transport Management, Vol. 9, 2003, p. 153-160.

[3] Ignaccolo M. Environmental capacity: noise pollution at Catania-Fontanarossa international airport. Journal of Air Transport Management, Vol. 6, 2000, p. 191-199.

[4] Janic M. Aviation and externalities: the accomplishments and problems. Transportation Research Part D: Transport and Environment, Vol. 4, 1999, p. 159-180.

[5] Sarakhs International Airport Report, 2014.

[6] United States Air Force, Draft Environmental Impact Statement, 2005.

[7] International Standards and Recommended Practices: Environmental Protection, Annex 16 to the Convention on International Civil Aviation, Volume I: Aircraft Noise. International Civil Aviation Organization (ICAO), 1993. 